\title{
BEBERAPA JENIS IKAN BAWAL (Angel fish, BRAMIDAE) YANG TERTANGKAP DENGAN RAWAI TUNA (TUNA LONG LINE) DI SAMUDERA HINDIA DAN ASPEK PENANGKAPANNYA
}

\author{
Abram Barata1) dan Budi Iskandar Prisantoso2) \\ 1) Observer pada Stasiun Monitoring Perikanan Tuna, Benoa-Bali \\ 2) Peneliti pada Pusat Riset Perikanan Tangkap, Jakarta \\ Teregistrasi I tanggal: 28 Mei 2008; Diterima setelah perbaikan tanggal: 28 Oktober 2008; \\ Disetujui terbit tanggal: 28 Nopember 2008
}

\begin{abstract}
ABSTRAK
Ikan bawal (Angel fish) yang menghuni perairan Samudera Hindia termasuk ke famili Bramidae. Rawai tuna (tuna long line) merupakan alat tangkap yang digunakan oleh kapal-kapal penangkap ikan di Pelabuhan Benoa untuk menangkap ikan bawal dan beberapa jenis ikan lainnya yang bernilai ekonomi tinggi. Ada tiga spesies ikan bawal yang tertangkap di Samudera Hindia, yaitu sickle pomfret (Taractichthys steindachneri), pomfret (Taractes rubescens), dan brilliant pomfret (Eumegistus illustris). Kisaran panjang cagak (fork length) ikan bawal yang tertangkap dengan tuna long line berkisar $<50$ $100 \mathrm{~cm}$. Kebanyakan ikan bawal tertangkap di kisaran kedalaman mata pancing 250-320 m dan suhu penangkapan antara $12-14^{\circ} \mathrm{C}$. Ikan bawal memiliki kebiasan makan pada pukul 18.00-21.30.
\end{abstract}

KATAKUNCI: $\quad$ bawal, Angel fish, rawai tuna, Samudera Hindia

\section{PENDAHULUAN}

Ikan bawal (angel fish) yang tertangkap di Samudera Hindia termasuk kelompok ikan oseanodrom, ikan yang hidup di laut dan mengadakan ruaya di laut (Effendie, 1997). Jenis ikan bawal yang tertangkap di Samudera Hindia adalah berbeda dengan jenis bawal yang tertangkap di perairan pantai seperti di Laut Jawa. Ikan bawal putih (pampus orgenteus) dan bawal hitam (formio niger) yang tertangkap di perairan pantai memiliki ukuran kecil dan tidak memiliki sisik. Bawal yang menghuni perairan Samudera Hindia memiliki tubuh gelap ataupun coklat kehitaman, sisik tebal, dan berukuran besar pada umur dewasa.

Ikan bawal yang tertangkap di Samudera Hindia termasuk ke dalam famili Bramidae. Ukuran ikan bawal yang tertangkap rata-rata di bawah $50 \mathrm{~cm}$ dan ada yang mencapai $100 \mathrm{~cm}$. Makanan ikan bawal berupa plankton, ikan-ikan pelagis kecil, dan kelompok cephalopoda. Pemijahan ikan bawal adalah ovipar, ikan yang mengeluarkan telur pada waktu pemijahan (Effendie, 1997).

Usaha perikanan tuna long line di Pelabuhan Benoa telah berlangsung cukup lama. Anonimus (2006) mengatakan bahwa sejak tahun 1973-sekarang, tuna long line telah mengalami perkembangan, baik dari segi armada kapal maupun aktivitas perusahaan (processing, eksportir, dan pengolahan ikan tuna). Hampir seluruh kapal penangkapan tuna di Benoa menggunakan rawai tuna. Alat tangkap rawai tuna tergolong alat tangkap pasif, memungkinkan beberapa jenis ikan tertangkap. Hasil tangkapan utamanya adalah tuna, namun beberapa hasil tangkapan sampingan yang memiliki nilai ekonomi yang tinggi, termasuk ikan bawal. Sampai saat ini, permintaan pasar terhadap ikan bawal cukup tinggi. Harga ikan bawal sangat berfluktuasi, pada musim paceklik, harga ikan bawal meningkat dari harga normal. Rawai tuna (tuna long line) merupakan alat tangkap produktif untuk menangkap ikan bawal di Samudera Hindia. Pengoperasian rawai tuna di Samudera Hindia memungkinkan beberapa jenis ikan bawal tertangkap, mulai dari ikan muda sampai dewasa. Ada perubahan bentuk fisik ikan bawal muda (bawal kecil) ke ukuran besar (bawal dewasa). Hal ini adalah salah suatu aspek yang menarik untuk diamati.

Penelitian ini bertujuan untuk mengidentifikasi jenis-jenis ikan bawal di Samudera Hindia yang dapat digunakan sebagai dasar panduan lapangan bagi para praktisi biologi perikanan maupun sebagai sumber pustaka untuk pengelolaan sumber daya ikan. Sedangkan dari aspek penangkapan bertujuan untuk mengetahui proses tertangkapnya ikan bawal berdasarkan pada suhu dan kedalaman mata pancing serta mengetahui kebiasaan waktu makan ikan bawal.

\section{BAHAN DAN METODE}

Data dikumpulkan melalui kegiatan observasi laut dengan K.M. Samodra 42 (2 trip) dan K.M. Samodra 37 (1 trip) yang dilengkapi oleh alat tangkap tuna long line. Alat-alat penunjang penelitian lainnya antara lain adalah 3 unit temperature depth recorder, 100 hook timer, kamera, handy tally count, dan meteran. Untuk 
mengetahui suhu dan kedalaman mata pancing digunakan temperature depth recorder. Sedangkan hook timer digunakan untuk menentukan waktu ikan memakan umpan pada pancing.

Identifikasi ikan bawal yang tertangkap dilakukan dengan mengacu referensi dari situs internet (www.fishbase.com) dan rujukan dari ahli taksonomi Commonwealth Scientific and Industrial Research Organization, Hobart Australia. Keterangan morfologi dan foto ikan menentukan penamaan spesies ikan bawal yang tertangkap.

\section{PENANGKAPAN IKAN BAWAL DENGAN MENGGUNAKAN RAWAI TUNA}

Pengoperasian rawai tuna di Benoa pada dasarnya dibedakan menjadi dua sistem, yaitu sistem arranger dan non arranger (blong dan basket). Menurut Sudirman \& Mallawa (2004), rawai terdiri atas tali pelampung (float line), rangkaian tali utama (main line) dengan jarak tertentu terdapat beberapa tali cabang (branch line) yang pendek dan lebih kecil diameternya dan di ujung tali cabang ini diikatkan pancing yang berumpan. Satu unit rawai tuna terdiri atas pelampung, tali pelampung, tali utama dengan sejumlah tali cabang yang berpancing bahan tali utamanya, dan tali cabang dapat terbuat dari bahan monofilamen (PA) dan bahan polyester (PE) seperti kuralon. Perbedaan pemakaian bahan ini mempengaruhi jenis line hauler yang diperlukan. Peneliltian pada K.M. Samodra 37 menggunakan sistem arranger dan pada K.M. Samodra 42 menggunakan sistem non arranger.

Pada sistem arranger, bahan tali pancing terbuat dari bahan kuralon. Diameter main line $7 \mathrm{~mm}$ dan tali cabangnya berdiameter $4 \mathrm{~mm}$. Penebaran tali utama tidak dilakukan secara manual tetapi menggunakan line shooter. Kecepatan setting tali utama sudah diatur antara 9-10 m per detik. Pemasangan tali cabang berpancing pada tali utama langsung dikaitkan dengan snape. Pada saat haulling, main line ditarik dengan hauler khusus yang dihubungkan melalui pipa panjang, menuju wadah penampung main line. Konstruksi tuna long line pada sistem ini lebih kuat dan jarang terjadi putus main line. Sedangkan sistem non arranger meliputi sistem blong dan basket ataupun perpaduan keduanya. Perbedaaannya dengan sistem arranger terletak pada bahan tali, hauller, penyusunan main line dan pemasangan branch line. Sistem non arranger lebih banyak dioperasikan secara manual. Bahan tali terbuat dari monofilamen yang berdiameter $3 \mathrm{~mm}$ untuk main line dan $2 \mathrm{~mm}$ untuk branch line. Penebaran main line dilakukan secara manual oleh anak buah kapal. Pada saat haulling, main line ditarik oleh hauller dan disusun pada blong-blong yang ada. Tali cabang dipasang pada tali penghubung (join line) yang dipasang pada tali utama. Pemasangan branch line pada main line menggunakan ikat simpul.

Pengoperasian tuna long line dengan sistem arranger dan non arranger pada prinsipnya adalah sama. Kedua sistem ini termasuk rawai tuna hanyut (drift tuna long line). Setiap anak buah kapal mempunyai tugas yang berbeda-beda. Saat setting (penebaran), ada yang bertugas memasang umpan, memasang tali cabang, menebar tali utama kecuali pada sistem arranger, memasang dan membuang pelampung, dan dua orang bertugas untuk mempersiapkan blong main line dan umpan. Jumlah mata pancing tiap pelampung yang digunakan adalah 16 dan 17 mata pancing. Mulai setting diawali dengan penurunan pelampung radio, kemudian diteruskan penebaran tali utama, pemasangan tali cabang berpancing antar pelampung bola, pemasangan tali pelampung bola, dan pada ujung tali utama kembali dipasang pelampung radio. Total setting adalah 4-5 jam. Pada akhir setting, alat tangkap dihanyutkan ke perairan dalam kurun waktu 3-5 jam (soak time). Sebelum memulai haulling (penarikan), diawali dengan mencari frekuensi pelampung radio yang menggunakan radio direction finder, sehingga dapat diketahui posisi alat tangkap berada. Saat haulling, seluruh anak buah kapal dilibatkan. Ada yang bertugas memegang kendali main line hauller, bertugas menyusun tali utama pada blong, menggulung tali cabang, menggulung tali pelampung, dan yang lain bersiap-siap jika terdapat ikan yang tertangkap ataupun terjadi kusut pada tali utama.

\section{HASIL TANGKAPAN}

Hasil tangkapan utama rawai tuna yang diperoleh di perairan Samudra Hindia yaitu big eye tuna (Thunnus obesus), yellow fin tuna (T. albacares), albacore ( $T$. alalunga), dan southern blue in tuna ( $T$. maccoyii). Hasil tangkapan sampingan meliputi lamadang, billfish, lancetfish, hiu (shark), pari (Plesiobatis sp.), layur (Trichiurus sp.), oilfish, moonfish, cakalang (Katsuwonus pelamis), tenggiri (Scomberomerous sp.), dan bawal. Terdapat berbagai spesies ikan bawal yang ditemukan di Samudera Hindia, baik itu ukuran kecil (bawal muda) maupun dewasa. Setiap jenis ikan bawal memiliki karakteristik morfologi tersendiri, baik dari bentuk badan, muka, maupun sirip. Adapun morfologi yang membedakan spesies-spesies ikan bawal tersebut adalah sebagai berikut: 
1. Taractes rubescens (pomfret):

- Bentuk muka lebih panjang.

- Badan memanjang dan berwarna hitam gelap.

- Pangkal ekor lebih panjang.

- Terdapat scute pada pangkal ekor.

2. Taractichthys steindachneri (sickle pomfret):

- Bentuk badan melebar.

- Sirip anal memanjang ke bawah.

- Sisik-sisik lebih lebar.

3. Eumegistus illustris (brilliant pomfret):

- $\quad$ Bagian tengah sirip ekor mempunyai 2 lekukan daripada bawal lain.

- $\quad$ Ujung sirip ekor berwarna putih perak.

4. Taractichthys steindachneri (sickle pomfret):

- $\quad$ Sirip dorsal dan sirip anal memanjang.

- $\quad$ Sirip ekor mempunyai lekukan kecil.

5. Taractichthys steindachneri (sickle pomfret)

- Bagian atas kepala lebih besar.

- Ujung sirip dorsal dan anal melengkung berwarna hitam.

\section{Taractichthys steindachneri (sickle pomfret)}

- Salah satu ujung sirip ekor lebih panjang.

- Terdapat scute pada pangkal ekor.

\section{Taractes rubescens (pomfret)}

- Bagian tepi sirip ekor berwarna putih.

- Bentuk badan pipih memanjang.

- Mata lebar.

Beberapa ikan bawal memiliki bentuk morfologi berbeda, walaupun dalam spesies yang sama. Hal ini, dikarenakan adanya perbedaan pertumbuhan umur pada saat ikan itu tertangkap. Secara umum, ikan bawal hidup bergerombol menurut jenis dan termasuk ikan beruaya jauh. Jenis sickle pomfret menghuni di lingkungan perairan yang sifat bentopelagis, artinya kelompok ikan ini secara bermusim menghuni di dasar sampai permukaan perairan. Jangkauan kedalaman renangnya adalah 50-700 m. Ikan bawal ini berada di
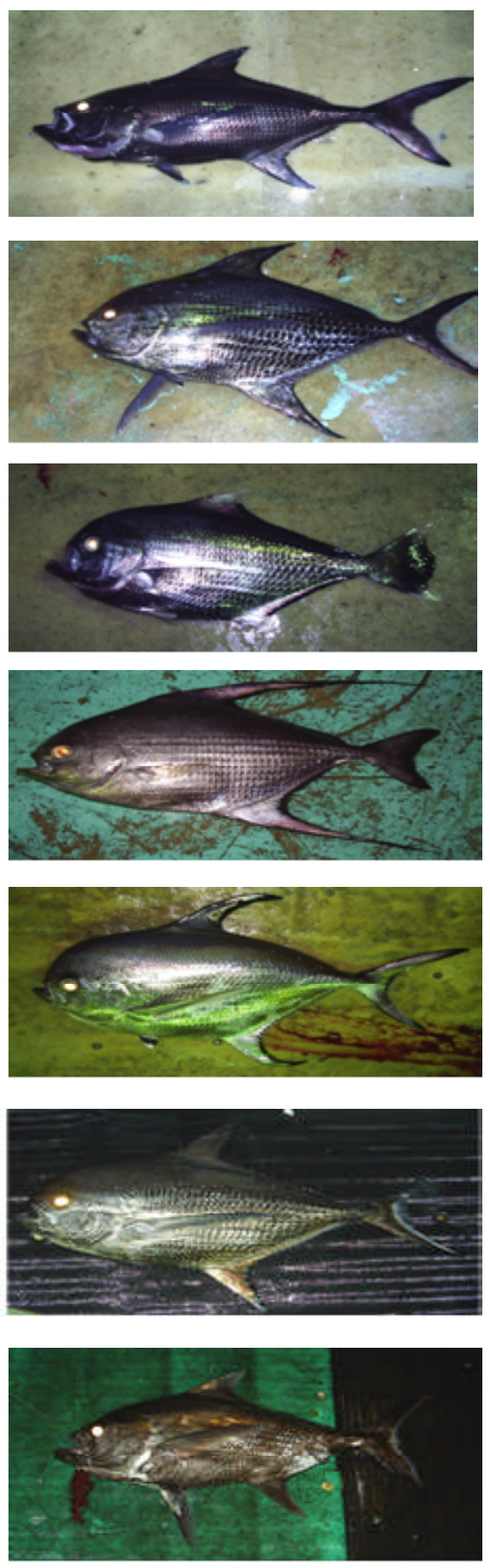

perairan laut tropis, sehingga jenis ikan bawal ini sering tertangkap di Samudera Hindia. Jenis brilliant pomfret tergolong penghuni laut bathypelagis, artinya beruaya pada tempat yang remang-remang, dingin, dan di permukaan samudera dalam. Jangkauan kedalaman renangnya adalah 1-520 m. Kebanyakan ikan bawal ini menghuni perairan laut dalam seperti di Samudera Pasifik dan selama observasi laut, ikan bawal ini jarang tertangkap. Ikan bawal jenis pomfret termasuk penghuni laut bentopelagis, sama dengan sickle 
pomfret. Jangkauan kedalaman renangnya adalah 1$400 \mathrm{~m}$ dan berada di perairan tropis. Selama observasi, jenis sickle pomfret lebih banyak tertangkap, diikuti oleh pomfret dan brilliant pomfret.

\section{UKURAN HASIL TANGKAPAN BAWAL}

Sebagian besar ikan bawal yang tertangkap memiliki kisaran panjang antara $30-50 \mathrm{~cm}$ (fork length), sedangkan panjang maksimun yang tertangkap dapat mencapai $100 \mathrm{~cm}$ (fork length) (Gambar 1, 2, dan 3).

\section{BAHASAN}

Berdasarkan pengamatan alat temperature depth recorder, ikan bawal yang tertangkap berada pada kedalaman 100-350 m dan suhu penangkapan berkisar $12-22^{\circ} \mathrm{C}$. Hal ini, dapat dilihat dari jumlah ikan bawal yang tertangkap berdasarkan pada posisi mata pancing.

Berdasarkan Gambar 4, ikan bawal banyak tertangkap pada posisi nomor pancing 6, 7, 9, dan 10. Pada posisi mata pancing ini kedalamannya

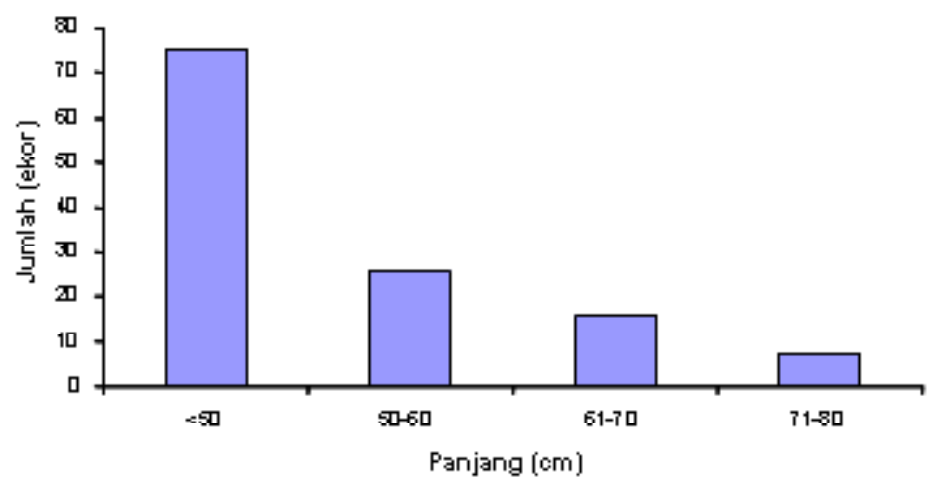

Gambar 1. $\quad$ Frekuensi panjang ikan bawal tertangkap pada K.M. Samodra 42 (29 Maret-21 April 2007).

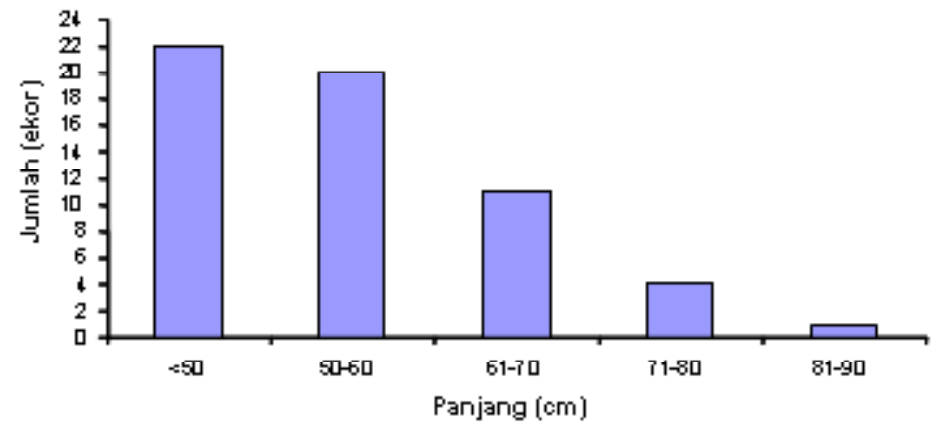

Gambar 2. Frekuensi panjang ikan bawal tertangkap pada K.M. Samodra 37 (14 Juni-7 Juli 2007).

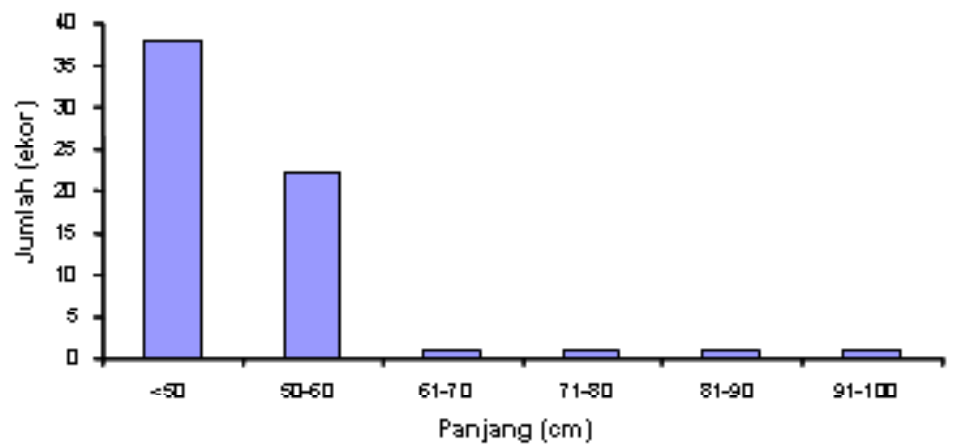

Gambar 3. Frekuensi panjang ikan bawal tertangkap pada K.M. Samodra 42 (29 Nopember-19 Desember 2007). 
adalah antara 250-320 m dengan suhu penangkapan antara $12-14^{\circ} \mathrm{C}$. Hal ini, sesuai dengan habitat ikan bawal tersebut, terutama jenis sickle pomfret yang dapat mencapai jangkauan kedalaman renang sampai $700 \mathrm{~m}$. Berkaitan dengan teknologi alat tangkap yang dioperasikan pada K.M. Samodra 37 dan K.M. Samodra 42, penangkapan ikan bawal sudah optimal. Apabila ingin memperoleh ikan bawal sebagai hasil tangkapan utama, jumlah mata pancing antar pelampung yang digunakan dapat ditambah atau dapat juga ditambah panjang tali pelampungnya sesuai dengan kedalaman yang diinginkan.

Hasil perhitungan menggunakan alat hook timer menunjukkan bahwa ikan bawal memiliki kebiasaan makan pada waktu sore sampai malam, khususnya antara pukul 18.00-21.30. Ada juga yang tertangkap pada pagi hari antara pukul 08.00-10.00, namun intensitas tertangkapnya sedikit. Ikan bawal lebih banyak tertangkap pada sore sampai malam hari dikarenakan pengaruh bulan terang. Ikan bawal beruaya naik ke permukaan dan aktif mencari makanan dengan kemampuan indera mata. Umpan yang digunakan adalah lemuru (Sardinella sp.), namun terkadang ikan bawal juga memburu ikan-ikan pelagis kecil seperti ikan layang (Decapterus sp.) dan cumi (Loligo sp.). Pada saat observasi, kegiatan mulai setting selalu dilakukan pagi (07.00-09.00) sampai siang hari (11.00-14.00). Untuk lebih efektif dalam menangkap ikan bawal, dapat diterapkan pola penangkapan waktu mulai setting pada sore hari terutama pada bulan terang.

Ikan bawal yang tertangkap kebanyakan memiliki ukuran di bawah $50 \mathrm{~cm}$. Ukuran tersebut adalah proses pertumbuhan ikan bawal menjadi dewasa. Menurut Smith (1986), jenis sickle pomfret mencapai panjang maksimun $60 \mathrm{~cm}$ (SL) dan berumur mencapai 8 tahun serta beruaya pada perairan yang lebih dalam. Kisaran kedalaman mata pancing yang dioperasikan apabila dalam keadaan tegak lurus dapat mencapai $400 \mathrm{~m}$. Ikan bawal yang tertangkap ada yang mencapai panjang maksimum $100 \mathrm{~cm}$ (fork length), yaitu jenis Taractes rubescens (pomfret), namun yang berukuran tersebut jarang tertangkap. Menurut Gomes (1990), jenis pomfret mencapai panjang maksimun $70 \mathrm{~cm}$ (SL) dan umur ikan mencapai 14 tahun.

\section{KESIMPULAN DAN SARAN}

\section{Kesimpulan}

1. Terdapat 3 spesies ikan bawal (angel fish) dari kelompok famili Bramidae, yaitu Taractichthys steindachneri, Taractes rubescens, dan Eumegistus illustris yang ditemukan di perairan Samudera Hindia.

2. Ikan bawal kebanyakan tertangkap pada kedalaman 250-320 m pada suhu penangkapan $12-14^{\circ} \mathrm{C}$.

3. Kebiasaan makan ikan bawal adalah pada pukul 18.00-21.30.

\section{Saran}

Perlu ada penelitian lanjutan yang berhubungan dengan aspek penangkapan pada kapal-kapal rawai tuna lain di Benoa yang menggunakan pancing dangkal.

\section{PERSANTUNAN}

Kegiatan dari hasil riset program observer tuna Samudera Hindia pada kapal-kapal tuna long line di Pelabuhan Benoa, T. A. 2007, kerja sama antara Pusat Riset Perikanan Tangkap dengan Australian Centre for International Agricultural Research.

\section{DAFTAR PUSTAKA}

Anonimus. 2006. Kondisi perikanan tuna long line di Benoa. Prosiding Seminar dan Evaluasi Monitoring Perikanan Tuna di Pelabuhan Benoa. Pusat Riset Perikanan Tangkap. Badan Riset Kelautan dan Perikanan. Departemen Kelautan dan Perikanan. (tidak dipublikasikan).

Effendi, M. I. 1997. Biologi Perikanan. Yayasan Pustaka Nusantara. Yogyakarta.

Gomes, J. 1990. Bramidae. p. 758-764. In J. C. Quero, J. C. Hureau, C. Karrer, A. Post, \& L. Saldanha (eds). Check list of the fishes of the eastern tropical Atlantic. JNCT, Lisbon; SEI. Paris; and UNESCO. Paris. Vol.2. http://www.fishbase.com/.

Smith, M. M. 1986. Bramidae. p. 633-636. In M. M. Smith and P. C. Heemstra (eds). Smith sea fishes. Springer-Verlag, Berlin. http://www.fishbase.com/

Sudirman \& A. Malllawa. 2004. Teknik Penangkapan Ikan. PT. Rineka Cipta. Jakarta. 